\title{
Clopidogrel in acute coronary syndrome prevention of recurrent ischaemia
}

\author{
Nishant Kumar Singh ${ }^{1 *}$, Sukhen Kumar Saha², Pragya Shahi ${ }^{3}$
}

13rd Year PGT, ${ }^{2}$ Professor, Department of General Medicine, ${ }^{3}$ MBBS. M.G.M. Medical College and L.S.K. Hospital, Kishanganj, Bihar, INDIA. Email: dr.nishantmed@gmail.com

Abstract Background: The term ACS applies to a category of clinical symptoms associated with acute myocardial infarction that spans the continuum of clinical conditions from severe angina to NSTEMI to STEMI. It is due to decreased blood flow in the arteries of the coronary so that part of the heart muscle cannot function properly or dies. Methods: It was prospective study. Patients presenting with unstable angina, non ST elevation myocardial infarction and ST elevation myocardial infarction were randomly selected from the outdoor and indoor of the department of Medicine M.G.M. Medical College and L.S.K. Hospital. Between January 2018 and December 2018. 150 patients of ACS were included in this study. 50 patients were randomised to receive aspirin (Group A), 50 patients received clopidogrel in (Group B) and 50 patients received the combination of aspirin and clopidogrel (Group C). Results: In our study, reduction of end points of MI, recurrent ischaemia, cardiac death and revascularisation was marginally better with clopidogrel (31.3\%) than aspirin $(42.5 \%)$ which was not significant $p>0.05$. This discrepancy between two studies may be due to differences in population under study, end points, duration of study, and number of patients. Conclusion: Combination of aspirin and clopidogrel is significantly more effective than either drug alone in secondary prevention of acute coronary syndromes. This benefit is evident at 30 days and it becomes more significant at 6 months.

Key Words: acute coronary syndromes, NSTEMI, STEMI, myocardial infarction, unstable angina.

*Address for Correspondence:

Dr Nishant Kumar Singh, 3rd Year PGT, Department of General Medicine, M.G.M. Medical College and L.S.K. Hospital, Kishanganj,

Bihar, INDIA.

Email: dr.nishantmed@gmail.com

Received Date: 07/11/2019 Revised Date: 11/12/2019 Accepted Date: 27/01/2020

DOI: https://doi.org/10.26611/10211533

This work is licensed under a Creative Commons Attribution-NonCommercial 4.0 International License. $(\mathbf{c c})$ EY-NC

\begin{tabular}{|l|l|}
\hline \multicolumn{2}{|c|}{ Access this article online } \\
\hline Quick Response Code: & Website: \\
\hline & www.medpulse.in \\
& \\
\hline
\end{tabular}

\section{INTRODUCTION}

The most common mechanism responsible for ACS is rupture of an atherosclerotic plaque that results in the partial or total occlusion of an epicardial coronary artery. Plaque disturbance reveals subendothelial collagen resulting in platelet activation and coagulation cascade resulting in thrombus formation. ${ }^{1}$ Loss of blood flow due to coronary occlusion and/or distal thrombus embolization via coronary microcirculation leads to symptoms of ischemic chest pain. Acute coronary syndrome is usually associated with three clinical symptoms, named after the presentation of the electrocardiogram (ECG): ${ }^{2}$ ST elevation of myocardial infarction ( STEMI, 30\%), non-ST elevation of myocardial infarction (NSTEMI, 25\%) or unstable angina $(38 \%)^{5}$. The cardinal symptom of severely decreased blood supply to the heart is chest pain, felt as tightness around or across the chest and radiating (often, but not always) to the left arm and the left jaw angle. Sweating, nausea and vomiting may be associated with this, as well as shortness of breath. The sensation is "atypical" in many situations, with pain felt in various ways or even entirely absent. Some might report palpitations, anxiety or a sense of impending doom and a feeling of acute illness. The definition of chest discomfort as a pressure is of little use in assisting a diagnosis since it is not unique to $\mathrm{ACS}^{3}$. Electrocardiogram A 12-lead electrocardiogram ( ECG) is the most critical specific examination in the initial evaluation of patients with ACS 
and should be conducted and checked within 10 minutes of the patient's arrival with suspected ACS. ${ }^{[4]}$ The presence of ST-segment elevation in 2 or more adjacent leads or a new left-bundle branch block (LBBB) in the correct clinical scenario distinguishes patients with suspected ACS. Findings such as transient elevation of the STsegment, STsegment depression and/or T-wave inversions support a high probability of ACS. In patients with clinical syndrome that is consistent with ACS, elevation in cardiac biomarkers signifies MI. Cardiac troponins T and I are the most sensitive and specific markers of myocardial necrosis In ACS pathogenesis platelets play a crucial function. Although activation of circulating platelets in response to vascular injury is necessary for normal hemostasis, their activation and aggregation in the sense of rupture or degradation of atherosclerotic plaque promotes the development of pathological thrombuses ${ }^{5}$. The blood vessels can occlude atherosclerotic plaque and thrombi, thereby blocking oxygen supply to the tissues and contributing to an ischemic event. It may result in stable or unstable angina, depending on the degree and extent of the blockage when the coronary arteries are affected; if the ischemia is extreme, the outcome is MI and necrosis. Aspirin was first recognized in the 1950 s to minimize the occurrence of $\mathrm{MI},{ }^{6}$ its action mechanisms remained unknown until 1967 when Weiss and Aledort ${ }^{7}$ published the first paper describing aspirin's inhibitory effects on platelets. Sir John R. Vane, ${ }^{8,9}$ who was awarded the Nobel Prize for his research, noticed a dose-dependent inhibition of prostaglandin formation with aspirin, salicylate, and indomethacin and offered more evidence for aspirin's therapeutic benefits. His research and the research of others have contributed to the discovery, in 1975 and 1976 respectively, of thromboxane $\mathrm{A} 2$ and prostacycline (PGI2). ${ }^{10,11}$

\section{METHODS}

It was prospective study. Patients presenting with unstable angina, non ST elevation myocardial infarction and ST elevation myocardial infarction were randomly selected from the outdoor and indoor of the department of Medicine M.G.M. Medical College and L.S.K. Hospital. Between January 2018 and December 2018. 150 patients of ACS were included in this study. 50 patients were randomised to receive aspirin (Group A), 50 patients received clopidogrel in (Group B) and 50 patients received the combination of aspirin and clopidogrel (Group C). Acute coronary syndromes, (i.e. unstable angina, ST segment elevation myocardial infarction, non ST segment elevation myocardial infarction) was diagnosed on the basis of detailed clinical history, examination, and special investigation findings recorded on a special proforma made for the study.

Treatment Protocol

The patients of ACS were randomised and divided into 3 groups. Patients in group 1 were given $325 \mathrm{mg}$ of aspirin as single loading dose, followed by $150 \mathrm{mg}$ once daily. Patients in group 2 were given $300 \mathrm{mg}$ of clopidogrel as single loading dose, followed by $75 \mathrm{mg}$ once daily. Patients in group 3 received combination of aspirin and clopidogrel 325 and $300 \mathrm{mg}$ respectively as loading dose, followed by $150 \mathrm{mg}$ and $75 \mathrm{mg}$ once daily. Other necessary medications were administered with the intention to treat. Follow up Protocol

Patients in all three groups were followed up in subsequent visits by-

- History taking and clinical examination.

- Complete haemogram, blood sugar, urea, creatinine, LFT.

- ECG

- Echocardiography, where indicated.

- Coronary angiography, where indicated.

During follow up, incidence of death from cardiovascular causes, new or recurrent MI, new or recurrent angina (UA), need for mechanical revascularisation, e.g. PTCA, CABG is noted as composite end points. Other standard treatments of ACS were given according to need of the patient.

\section{RESULTS}

Total 150 patients of ACS were included in this study. 50 patients were randomised to receive aspirin (Group A), 50 patients received clopidogrel in (Group B) and 50 patients received the combination of aspirin and clopidogrel (Group C).

Among them, 135 patients completed the study period (40 in group A, 48 in group B, and 47 in group C). Rest 15 patients either did not complete the study or died, so were excluded from the study.

\begin{tabular}{|c|c|c|c|c|c|c|}
\hline \multirow[b]{2}{*}{ Age } & \multicolumn{2}{|c|}{$\begin{array}{l}\text { Group -A } \\
\text { (Aspirin) }\end{array}$} & \multicolumn{2}{|c|}{$\begin{array}{c}\text { Group- B } \\
\text { (Clopidogrel) }\end{array}$} & \multicolumn{2}{|c|}{$\begin{array}{c}\text { Group- C } \\
\text { (Aspirin+Clopidogrel) }\end{array}$} \\
\hline & Mean & SD & Mean & SD & Mean & SD \\
\hline & 55.97 & \pm 1.90 & 55.39 & \pm 2.22 & 55.21 & \pm 2.35 \\
\hline \multicolumn{7}{|c|}{ Chi- square- 12.085 p Value- 0.738 (NS) } \\
\hline
\end{tabular}


Table 2: Sex distribution among three groups

\begin{tabular}{|c|c|c|c|c|c|c|}
\hline \multirow[t]{2}{*}{ Sex } & \multicolumn{2}{|c|}{$\begin{array}{c}\text { Group -A } \\
\text { (Aspirin) } \\
(n=40)\end{array}$} & \multicolumn{2}{|c|}{$\begin{array}{c}\text { Group- B } \\
\text { (Clopidogrel) } \\
(n=48)\end{array}$} & \multicolumn{2}{|c|}{$\begin{array}{c}\text { Group- C } \\
\text { (Aspirin+Clopido } \\
\text { grel) } \\
(n=47)\end{array}$} \\
\hline & No & $\%$ & No & $\%$ & No & $\%$ \\
\hline Male & 31 & 77.5 & 36 & 75.0 & 37 & 78.7 \\
\hline Female & 09 & 22.5 & 12 & 25.0 & 10 & 21.3 \\
\hline Total & 40 & 100 & 48 & 100 & 47 & 100 \\
\hline
\end{tabular}

Table 3: Demographic profile distribution among three groups

\begin{tabular}{ccccccc}
\hline Demographic profile & $\begin{array}{c}\text { Group -A (Aspirin) } \\
(\mathrm{n}=\mathbf{4 0})\end{array}$ & $\begin{array}{c}\text { Group- B (Clopidogrel) } \\
(\mathrm{n}=\mathbf{4 8})\end{array}$ & $\begin{array}{c}\text { Group- C (Aspirin+Clopidogrel) } \\
(\mathrm{n}=47)\end{array}$ \\
\cline { 2 - 7 } & No & $\%$ & No & $\%$ & No & $\%$ \\
\hline Current smoking & 13 & 32.5 & 12 & 25.0 & 15 & 31.9 \\
Hypertension & 18 & 45.0 & 19 & 39.6 & 19 & 40.4 \\
Hyperlipidemia & 13 & 32.5 & 12 & 25.0 & 14 & 29.8 \\
Diabetes & 12 & 30.0 & 15 & 31.3 & 11 & 23.4 \\
Obesity & 07 & 17.5 & 09 & 18.8 & 07 & 14.9 \\
H/O IHD & 19 & 47.5 & 17 & 35.4 & 14 & 29.8 \\
& \multicolumn{7}{c}{$\chi^{2}=2.238, p$ Value $=0.994$} \\
\hline
\end{tabular}

Table:4. Clinical profile distribution among three groups.

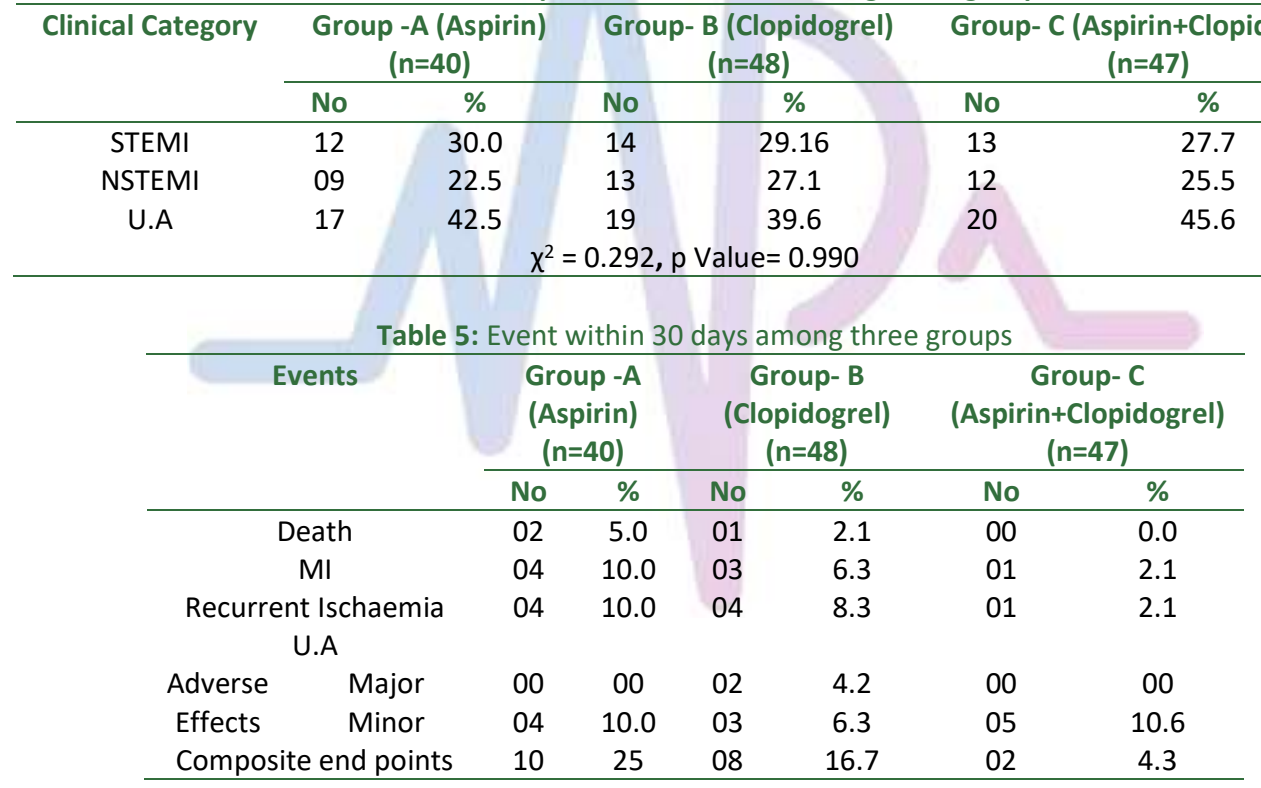

Table 6: Event within 6 months among three groups

\begin{tabular}{|c|c|c|c|c|c|c|}
\hline \multirow[t]{2}{*}{ Events } & \multicolumn{2}{|c|}{$\begin{array}{c}\text { Group -A } \\
\text { (Aspirin) } \\
(n=40)\end{array}$} & \multicolumn{2}{|c|}{$\begin{array}{c}\text { Group- B } \\
\text { (Clopidogrel) } \\
(n=48)\end{array}$} & \multicolumn{2}{|c|}{$\begin{array}{c}\text { Group- C } \\
\text { (Aspirin+Clopidogrel) } \\
(n=47)\end{array}$} \\
\hline & No & $\%$ & No & $\%$ & No & $\%$ \\
\hline Death & 03 & 7.5 & 02 & 4.2 & 00 & 00 \\
\hline $\mathrm{MI}$ & 06 & 15.0 & 05 & 10.4 & 02 & 4.3 \\
\hline $\begin{array}{c}\text { Recurrent Ischaemia } \\
\text { U.A }\end{array}$ & 08 & 20.0 & 08 & 16.7 & 03 & 6.4 \\
\hline Adverse $\quad$ Major & 00 & 00 & 02 & 4.2 & 00 & 00 \\
\hline Effects Minor & 07 & 17.5 & 06 & 12.5 & 07 & 14.9 \\
\hline Composite end points & 17 & 42.5 & 15 & 31.3 & 05 & 10.6 \\
\hline
\end{tabular}




\section{DISCUSSION}

It is clear today that acute coronary syndromes result from a complex pathophysiological process of disruption of atheromatous plaque with superimposed platelet adhesion, activation, and aggregation, followed by activation of coagulation cascade and subsequent thrombus formation, Since platelets have a major role in this disease spectrum, antiplatelet therapy plays a central role in treatment and secondary prevention of acute coronary syndromes. As antiplalelet drug, aspirin has been the only available option for last several decades. Recently several new antiplatelet agents has been marketed among which clopidogrel seems to be most promising. In CAPRIE trial, clopidogrel was compared with aspirin regarding its role in prevention of thrombotic events in patients at high risk of ischaemic events. CURE investigators compared efficacy of combination of clopidogrel and aspirin with aspirin alone in patients with acute coronary syndromes without STelevation. But till date no study has been done to compare efficacy of clopidogrel, aspirin and their combination in the background of acute coronary syndromes. Hence our prospective study has been designed to evaluate the efficacy of clopidogrel, alone or in combination with aspirin in secondary prevention of acute coronary syndromes. In our study, reduction of end points of MI, recurrent ischaemia, cardiac death and revascularisation was marginally better with clopidogrel $(31.3 \%)$ than aspirin $(42.5 \%)$ which was not significant $p>0.05$. This discrepancy between two studies may be due to differences in population under study, end points, duration of study, and number of patients. CURE study ${ }^{12}$, which is another important randomised, placebo controlled double blind trial, has been designed to show the benefit of adding clopidogrel to the regimen of treatment for patients with acute coronary syndromes without ST segment elevation who are receiving aspirin and other medications. Dose of clopidogrel was $300 \mathrm{mg}$ single loading dose followed by $75 \mathrm{mg} /$ day, similar to our study. Aspirin was given at the dose of 75-325 mg daily. Follow up period was 3 to 12 months with mean duration of 9 months. The first primary outcome,- death from cardiovascular causes, non fatal myocardial infarction or stroke - occurred in $4.3 \%$ patients in combination (aspirin plus clopidogrel) group as compared with $15.0 \%$ patients in aspirin group. $(\mathrm{P}<0.001)$. The rate of second primary outcome- first primary outcome plus refractory ischaemia, was also significantly less in combination group $(6.4 \%$ in combination group versus $20.0 \%$ in aspirin group). This result was expected because theoretically aspirin and clopidogrel inhibit two different steps in platelet aggregation (viz. Production and release of Thromboxane $\mathrm{A}_{2}$, and blockade of ADP receptors respectively) and their efficacy are additive. The incidences of cardiac event were first evaluated at day 30 .
It was observed that death occurred in 2,1 and 0 patients in groups $\mathrm{A}, \mathrm{B}$, and $\mathrm{C}$ respectively. Incidence of MI were 4,3 , 1; i.e. $10.0 \%, 6.3 \%, 2.1 \%$ respectively. Recurrent unstable angina developed in 4,4 , and 1 patient respectively, i.e. $10.0 \%, 6.3 \%$. $2.1 \%$ of patients. Altogether composite end points occurred in 10 patients in group A $(25.0 \%), 8$ patients in group B $(16.7 \%)$ and 2 patients in group C (4.3\%) at the end of 30 days. Analysis showed composite end points were significantly less in group 3 in comparison to group A and group $B(Z=2.48$ and 1.63 respectively, $\mathrm{P}<0.05)$. On the other hand, difference of reduction of composite end points were not significant between group A and B. ( $Z=0.70 \mathrm{p}$ value- 0.24 ) There was two incidence of major adverse effect (viz. Intracranial haemorrhage) within 30 days which occurred in group B. Minor adverse effects occurred in 4 patients of group A (10.0\%), 3 patients of group B $(6.2 \%)$, and 5 patients in group $\mathrm{C}(10.6 \%)$. The difference was not statistically significant. [ $(\mathrm{P}>0.1)$ Patients were followed up for 6 months. At the end of 6 months events were analysed by combining events within 30 days and events those occurred between day 31 and the end of 6 months. Total incidence of death were 3,2 and 0 in groups A,B, and C respectively. Incidences of MI were 6,5 and 2 in respective groups, i.e. $15.0 \%, 10.4 \%$, and $4.3 \%$ patients. During this period UA occurred in 8,8 and 3 patients respectively, i.e. $20.0 \%, 16.7 \%$, and $6.4 \%$ of patients. Overall incidence of composite end points were 17, 15, and 5 patients i.e. $42.5 \%, 31.3 \%$ and $10.6 \%$ in groups $\mathrm{A}, \mathrm{B}$, and $\mathrm{C}$ respectively. Analysis showed that benefit of combination therapy (Group C) was still persisting at the end of 6 months (For Group A and Group C, $Z=3.17$ i.e. $\mathrm{P}<0.001$, for Group B and Group C, $(Z=2.22$ i.e. $p$ Value - 0.01$)$. On the other hand, ability of clopidogrel in reducing composite end points in comparison to aspirin was marginally superior but did not assume statistical significance. ( $\mathrm{Z}=0.86, \mathrm{p}$ Value- 0.19$)$ There was no further major adverse effect between 31st day and end of 6 months i.e. overall major adverse effect occurred in 2 patient in Group B as mentioned earlier. Total incidence of minor adverse effects were 7, 6 and 7 i.e. $17.5 \%, 12.5 \%$ and $14.9 \%$ respectively. There is no statistically significant difference $(\mathrm{P}>0.1)$. There was no evidence of haematological, renal or hepatic dysfunction in any of the groups. Our study is not only consistent with result of CURE, i.e. Combination is better than aspirin, but it also shows that combination is better than clopidogrel alone. Regarding adverse effects observed in CAPRIE, incidence of rash and diarrhoea were significantly more in clopidogrel group, whereas incidence of nausea, vomiting, indigestion; gastrointestinal haemorrhage, and abnormal liver functions were more in aspirin group. Incidences of bleeding, thrombocytopenia and neutropenia were not 
significantly different between two groups. In CURE trial, combination of clopidogrel with aspirin resulted in significantly increased incidence of major and minor bleeding. In our study, major adverse effect, which required discontinuation of therapy, occurred in only one patient in clopidogrel group (viz. intracerebral haemorrhage). Hence, its significance could not be compared with other groups. Incidences of minor adverse effects were not significantly different among three groups. Less incidence of bleeding in our study may be due to smaller sample size. There was no incidence of thrombocytopenia or neutropenia in our study.

\section{CONCLUSION}

Combination of aspirin and clopidogrel is significantly more effective than either drug alone in secondary prevention of acute coronary syndromes. This benefit is evident at 30 days and it becomes more significant at 6 months. Ability of clopidogrel in reducing composite end points is marginally superior in comparison to aspirin but the difference is not statistically significant.Incidences of adverse effects are not significantly different among three groups.

\section{REFERENCES}

1. Go AS, Mozaffarian D, Roger VL, et al. . Executive summary: heart disease and stroke statistics-2013 update: a report from the American Heart Association. Circulation. 2013;127(1):143-152.

2. Grech ED, Ramsdale DR (June 2003). "Acute coronary syndrome: unstable angina and non-ST segment elevation myocardial infarction". BMJ. 326 (7401): 1259-61.
3. Woo KM, Schneider JI (November 2009). "High-risk chief complaints I: chest pain--the big three". Emerg. Med. Clin. North Am. 27 (4): 685-712.

4. Antman EM, Anbe DT, Armstrong PW, et al.. ACC/AHA guidelines for the management of patients with STelevation myocardial infarction-executive summary. A report of the American College of Cardiology/American Heart Association Task Force on Practice Guidelines (Writing Committee to revise the 1999 guidelines for the management of patients with acute myocardial infarction). J Am Coll Cardiol. 2004;44(3):671-719.

5. Stakos DA, Tziakas DN, Stellos K. Mechanisms of platelet activation in acute coronary syndromes. Curr Vasc Pharmacol. 2012;10(5):578-588.

6. Craven L Experiences with aspirin (acetylsalicyclic acid) in the nonspecific prophylaxis of coronary thrombosis. Miss Valley Med J. 1953;7538- 40.

7. Weiss HJAledort LM Impaired platelet-connective-tissue reaction in man after aspirin ingestion. Lancet. 1967;2495- 497.

8. ane JR Inhibition of prostaglandin synthesis as a mechanism of action for aspirin-like drugs. Nat New Biol. 1971;231232- 235.

9. Ferreira SHMoncada SVane JR Indomethacin and aspirin abolish prostaglandin release from the spleen. Nat New Biol. 1971;231237- 239.

10. amberg MSvensson JSamuelsson B Thromboxanes: a new group of biologically active compounds derived from prostaglandin endoperoxides. Proc Natl Acad Sci US A. 1975;722994- 2998.

11. Moncada SGryglewski RBunting SVane JR An enzyme isolated from arteries transforms prostaglandin endoperoxides to an unstable substance that inhibits platelet aggregation. Nature. 1976;263663- 665.

12. Cannon $\mathrm{CP}$, McCabe $\mathrm{CH}$, Wilcox $\mathrm{RG}$, et al. Oral glycoprotein Iib / IIIa inhibition with orbofiban in patients with unstable coronary syndromes( OPUS-TIMI 16) trial. Circulation $2000 ; 102: 149-156$.

\section{Source of Support: None Declared Conflict of Interest: None Declared}

Policy for Articles with Open Access:

Authors who publish with MedPulse International Journal of Medicine, Print ISSN: 2550-7583, Online ISSN: 2636-4751 agree to the following terms: Authors retain copyright and grant the journal right of first publication with the work simultaneously licensed under a Creative Commons Attribution License that allows others to share the work with an acknowledgement of the work's authorship and initial publication in this journal. Authors are permitted and encouraged to post links to their work online (e.g., in institutional repositories or on their website) prior to and during the submission process, as it can lead to productive exchanges, as well as earlier and greater citation of published work. 